\title{
Plant Growth Promotion by Spermidine-Producing Bacillus subtilis OKB105
}

\author{
Shan-Shan Xie, Hui-Jun Wu, Hao-Yu Zang, Li-Ming Wu, Qing-Qing Zhu, and Xue-Wen Gao \\ Department of Plant Pathology, College of Plant Protection, Nanjing Agricultural University, Key Laboratory of Integrated \\ Management of Crop Diseases and Pests, Ministry of Education, Nanjing 210095, PR China
}

Submitted 16 January 2014. Accepted 14 March 2014.

The interaction between plants and plant-growth-promoting rhizobacteria (PGPR) is a complex, reciprocal process. On the one hand, plant compounds such as carbohydrates and amino acids serve as energy sources for PGPR. On the other hand, PGPR promote plant growth by synthesizing plant hormones and increasing mineral availability in the soil. Here, we evaluated the growthpromoting activity of Bacillus subtilis OKB105 and identified genes associated with this activity. The genes yec $A$ (encoding a putative amino acid/polyamine permease) and $\operatorname{speB}$ (encoding agmatinase) are involved in the secretion or synthesis of polyamine in B. subtilis OKB105. Disruption of either gene abolished the growth-promoting activity of the bacterium, which was restored when polyamine synthesis was complemented. Moreover, high-performance liquid chromatography analysis of culture filtrates of OKB105 and its derivatives demonstrated that spermidine, a common polyamine, is the pivotal plantgrowth-promoting compound. In addition, real-time polymerase chain reaction analysis revealed that treatment with $B$. subtilis OKB105 induced expansin gene (Nt-EXPA1 and $N t-E X P A 2)$ expression and inhibited the expression of the ethylene biosynthesis gene $A C O 1$. Furthermore, enzymelinked immunosorbent assay analysis showed that the ethylene content in plant root cells decreased in response to spermidine produced by OKB105. Therefore, during plant interactions, OKB105 may produce and secrete spermidine, which induces expansin production and lowers ethylene levels.

Plant-growth-promoting rhizobacteria (PGPR) are naturally occurring soil microorganisms that aggressively colonize plant roots and benefit plants by increasing plant growth or reducing disease. Several Bacillus spp. representing typical PGPR have been widely studied and applied as efficient, stable biocontrol agents due to their ability to form heat- and desiccationresistant spores. Several Bacillus spp.-based products have recently been commercialized, including YIB (Bacillus spp.), Quantum-400 (Bacillus subtilis strain GB03), Serenade (B. subtilis, strain QST713), Kodiak (B. subtilis, improved GB03 strain), and Rhizovital (B. amyloliquefaciens, strain FZB42)

Corresponding author: X.-W. Gao; Telephone/Fax: +1 86-25-84395268; E-mail: gaoxw@njau.edu.cn

* The $\boldsymbol{e}$-Xtra logo stands for "electronic extra" and indicates that Figure 1 appears in color online.

(C) 2014 The American Phytopathological Society
(Brannen and Kenney 1997; Ngugi et al. 2005). Bacillus spp. promote plant growth; the proposed mechanisms for plant growth promotion by Bacillus spp. include increasing mineral, nitrogen, and phosphorus availability in the soil (Idriss et al. 2002) and synthesizing plant hormones (Gutiérrez-Mañero et al. 2001; Idris et al. 2007; Ortíz-Castro et al. 2008). Moreover, Bacillus spp. can also protect plants against soil-borne diseases through antibiotic production, predation and parasitism, competition for ferric iron ions, competition for nutrients and niches, and induction of plant resistance (Pliego et al. 2008; Van Peer et al. 1991).

The interaction between plants and PGPR is a complex, reciprocal process. This relationship is initiated through the action of compounds such as malic acid, which is released by the plant to attract rhizobacteria, causing the subsequent migration of microorganisms towards the roots, bacterial movement along the roots, and adherence (Rudrappa et al. 2008). Maize root exudates contribute to the chemotaxis and motility of B. amyloliquefaciens FZB42 (Fan et al. 2012). Another study suggested that L-malic acid secreted from Arabidopsis roots selectively signals and recruits the beneficial rhizobacterium B. subtilis FB17 (Rudrappa et al. 2008). Biofilm formation is important for the root colonization of plants (Ramey et al. 2004). After colonization, the PGPR can take up and utilize carbohydrates and amino acids released by the plant and, in turn, PGPR produce bioactive substances to promote plant growth or to suppress disease. For example, phytases produced by B. amyloliquefaciens FZB45 solubilize phosphate from organic bound phosphates, thereby facilitating the growth of maize seedlings (Idriss et al. 2002). In addition to their action as biofertilizers, Bacillus spp. are also regarded as phytostimulators due to their production of plant hormones such as indole-3-acetic acid (Idris et al. 2007), cytokinin (Ortíz-Castro et al. 2008), and gibberellins (GutiérrezMañero et al. 2001). Recently, volatiles produced by Bacillus spp. were also suggested to help increase plant growth. Moreover, Bacillus spp. produce a variety of bioactive antibiotic metabolites, such as lipopeptides and polyketides. The iturin and fengycin families of lipopeptides play a major role in the antagonism of B. subtilis toward Podosphaera fusca (Romero et al. 2007). Furthermore, fengycin- and surfactin-type lipot pepides can function as bacterial determinants in plant cells by initiating the immune response through the stimulation of induced systemic resistance (Ongena et al. 2007). The difficidin and bacilysin families of polyketides, which are produced by plant-associated B. amyloliquefaciens, are efficient at controlling fire blight disease (Chen et al. 2009).

Polyamines, including putrescine, spermine, spermidine, and cadaverine, are natural, small-molecular-weight polycationic compounds with positive charges that are present in mammals, 
fungi, bacteria, and plants. Polyamines play important physiological roles in organisms and are involved in various processes, including cell division and differentiation, nucleic acid replication, transcription, translation, protein synthesis, and membrane stability (Kusano et al. 2008; Wortham et al. 2007). Moreover, spermidine has attracted widespread interest because it is essential for eukaryotic cell viability and is correlated with lateral root development. A double mutant of two spermidine synthaseencoded genes, SPDS1 and SPDS2, exhibits a lethal defect in embryo development (Imai et al. 2004). A decrease in spermidine and spermine levels results in reduced lateral root development (Hummel et al. 2002). Spermidine also plays a protective role against various stresses, including oxidative, acidic, and osmotic stresses as well as pathogen attacks. For instance, overexpression of the Cucurbita ficifolia SPDS gene confers multi-stress tolerance to Arabidopsis and sweet potato (Kasukabe et al. 2004). Genes involved in polyamine biosynthesis are upregulated in tobacco plants that were inoculated with Tobacco mosaic virus, and inhibitors of polyamine biosynthesis suppress the accumulation of polyamines and the rate of the hypersensitive response as well (Yoda et al. 2003). To date, studies on the impact of polyamines on the plant growth, stress responses, and diseases have been conducted but only a few studies have focused on polyamines produced by PGPR. Cassan et al. (2009) demonstrated that Azospirillum

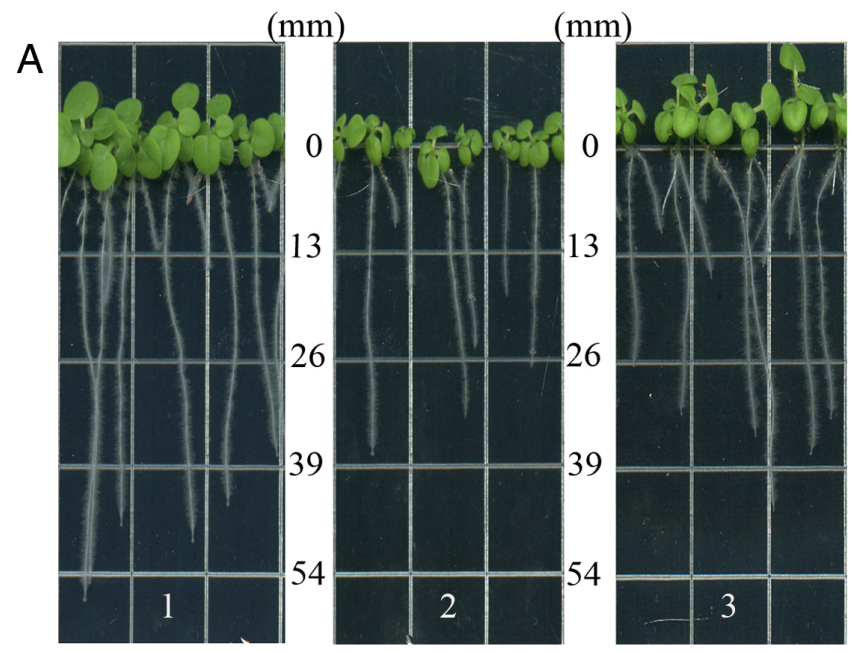

B

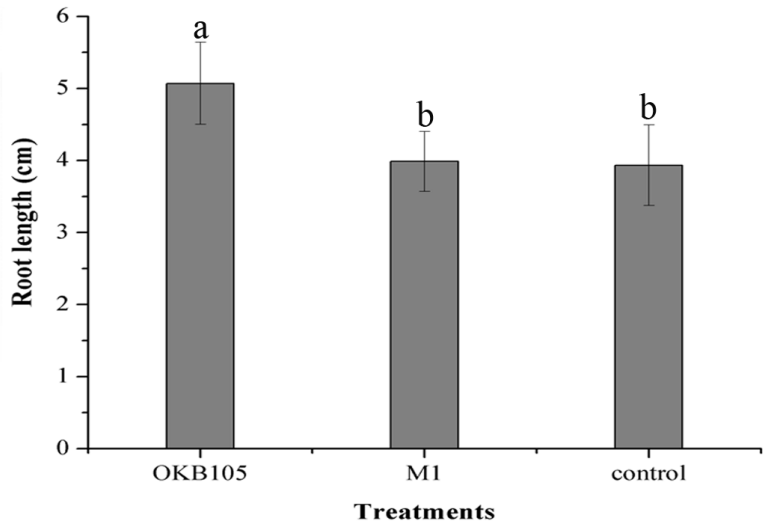

Fig. 1. Effects of Bacillus subtilis OKB105 mutant M1 on root growth in Nicotiana tabacum. Column $1=$ B. subtilis OKB105; column $2=$ M1 (random mutant OKB105yecA::TnYLB-1); column 3 = control. A, Tobacco (N. tabacum) seed were first soaked with culture filtrates of B. subtilis OKB105, random mutant OKB105yecA::TnYLB-1, and control; then, the root lengths were measured at 20 days. B, Quantification of root growth. Different letters indicate statistical differences between treatments (Fisher's least significant difference, $P \leq 0.05$ ). brasilense Az39 promotes root growth in rice seedlings, partly due to cadaverine production.

In a previous study, we demonstrated that $B$. subtilis OKB105 significantly promotes root growth in tobacco. Analysis based on the complete genome sequence revealed that clusters of cytokinin and gibberellin biosynthetic genes are not present in the genome of $B$. subtilis OKB105, although some genes involved in tryptophan-dependent indole-3-acetic acid (IAA) biosynthesis were identified. IAA was not detected in culture filtrates of B. subtilis OKB105, suggesting that the plantgrowth-promoting activity of OKB105 is not due to metabolites already shown to be involved in this process. The aim of this study was to identify the growth-promoting substance in the culture filtrates of $B$. subtilis OKB105 to gain insights into the underlying mechanisms responsible for the growth-promoting ability of this bacterium. The results suggest that spermidine produced by $B$. subtilis OKB 105 can promote root growth in tobacco by inducing the expression of the expansin genes $N t-E X P A 1$ and $N t-E X P A 2$ and by reducing the ethylene content in root cells.

\section{RESULTS}

\section{Screening of mutant libraries and identification of plant growth promotion-related genes.}

By examining the growth of tobacco seedlings in the culture filtrates of $B$. subtilis OKB105, we determined that this bacterium could significantly promote the growth of tobacco roots; the root growth of the treated plants increased by $55.9 \%$ compared with the control. To identify genes associated with plant growth promotion, we constructed an OKB105 mutant library using the pMarA plasmid. After screening 700 mutants, we isolated a mutant defective in promoting plant growth, which we designated M1 (Fig. 1). To identify the gene loci present in the transposon insertional mutant $\mathrm{M} 1$, the inserted transposon and its flanking regions were cloned by inverse polymerase chain reaction (PCR) and sequenced. The insertion of the TnYLB-1 transposon was located in the yecA gene. To confirm that the $y e c A$ gene is associated with plant growth promotion, we constructed a site-directed mutant, OKB105 1 yecA, using doublecrossover homologous recombination. Treatment with culture filtrates of OKB105 $\mathrm{yecA}$ did not promote the growth of plant roots. These results indicate that yecA is important in promoting plant growth. The yecA gene encodes a putative amino acid/polyamine permease. We hypothesize that the polyamine synthesized by the OKB105 strain is effluxed by the yecA gene product and then is utilized by the plants.

\section{Construction of mutants and their growth-promoting activities.}

The spe $B$ gene, which encodes agmatinase, is a key gene involved in the biosynthesis of polyamines in B. subtilis, and disruption of $s p e B$ abolishes the production of polyamines such as putrescine and spermidine (Fig. 2). To confirm the role of polyamines in the PGPR-plant interaction, the speB gene was disrupted by double-crossover homologous recombination. Furthermore, the B. subtilis OKB105 speB mutant was complemented with the entire $s p e B$ gene fused to the $a m y E$ gene. We first investigated the expression level of $s p e B$ in $B$. subtilis $\mathrm{OKB} 105 \Delta$ spe $B$ and in the complemented transformant. Real-time PCR analysis revealed that the expression level of $s p e B$ in the complemented transformant corresponded to that of OKB105 but speB expression in B. subtilis OKB105 speB was not detected (Fig. 3). Second, we tested the growth-promoting activity of the mutants. Treatment with the complemented transformant resulted in an increase in tobacco root elongation similar to that obtained with wild-type OKB105, 
whereas the addition of culture filtrates obtained from the OKB105 $\Delta$ speB mutant did not increase root growth (Fig. 4A). The growth-promoting activity of OKB105 disappeared when biosynthesis or excretion of polyamines was abolished. These results suggest that the growth-promoting effect of $B$. subtilis OKB105 is related to polyamines.

\section{Identification and quantification} of the growth-promoting substance.

Bacteria primarily synthesize two types of polyamines, putrescine and spermidine (Wortham et al. 2007). To detect the kinds of the polyamines in the culture filtrates of OKB105, the high-performance liquid chromatography (HPLC) analysis was performed. The results had demonstrated that putrescine was not detected, whereas spermidine was present in OKB105 and its corresponding complemented transformant in concentrations of 7.36 and $5.48 \mu \mathrm{M}$, respectively. By contrast, spermidine was completely absent in the culture filtrates of OKB105 yecA and OKB105 $\Delta$ speB (Fig. 5A). Moreover, intra-

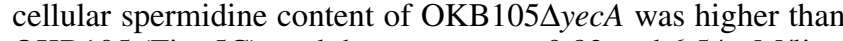
OKB105 (Fig. 5C), and the content was 9.82 and $6.54 \mu \mathrm{M} /$ liter of bacterium, respectively. To determine whether the growthpromoting substance was indeed spermidine, we applied dicyclohexylamine (DCHA), an inhibitor of spermidine synthase (Hibasami et al. 1980; Torrigiani et al. 1987), directly to the growth medium of OKB105. This resulted in the depletion of spermidine and the abolishment of plant-growth-promoting activity (Figs. 4B and 5B).

\section{The role of spermidine in plant-growth promotion.}

We conducted experiments to study the effects of different concentrations of spermidine on root growth in tobacco. Spermidine in concentrations of 5 to $100 \mu \mathrm{M}$ enhanced root elongation, whereas spermidine at $1,000 \mu \mathrm{M}$ did not have a positive effect on root growth. The dose-response curve with exogenous spermidine in the presence of tobacco seedlings confirms the efficacy of spermidine in promoting plant growth (Fig. 6). Overall, the current study indicates that exogenous spermidine at optimum concentrations can promote tobacco growth.

\section{Expression of growth-related genes in tobacco.}

To explore the effects of the spermidine produced by OKB105 on plant gene expression, we examined the expression of Nt-EXPA1, Nt-EXPA2, and ACO1 in tobacco. Nt-EXPA1 and $N t-E X P A 2$ encode tobacco expansin proteins that loosen cell walls and promote cell division and extension (Choi et al. 2003). The ACO1 gene encodes 1-aminocyclopropane-1-carboxylic acid oxidase, which is a key enzyme regulating ethy- lene production. Real-time PCR analysis revealed that $\mathrm{Nt}$ EXPA1 and Nt-EXPA2 were upregulated and ACO1 was downregulated in response to the culture filtrates of OKB105 and the wild-type-complemented transformant as well as synthetic spermidine. However, these genes were not differentially expressed in response to culture filtrates of OKB105 $\Delta$ speB, which is impaired in spermidine production (Fig. 7). Expansins encoded by Nt-EXPA1 and Nt-EXPA2 are primary wallloosening agents which can stimulate cell enlargement, and their expression change can modify plant growth (Cosgrove 2005). Moreover, they begin to function in seconds; after expansin addition, isolated walls begin to creep at a fast rate (McQueen-Mason et al. 1992). This indicates that spermidine produced by OKB105 may regulate cell wall enlargement through altering the expression of $N t$-EXPA genes.

\section{Quantification of ethylene content in tobacco.}

Because $A C O 1$ was downregulated in response to the culture filtrates of OKB105, the wild-type complemented transformant, and synthetic spermidine, we analyzed changes in ethylene content in tobacco in response to these treatments using a plant ethylene enzyme-linked immunosorbent assay (ELISA) kit. Ethylene content was also reduced in the presence of culture filtrates of OKB105, the wild-type complemented transformant strain, and synthetic spermidine, while treatment with culture filtrate of OKB105 $\Delta$ speB did not affect

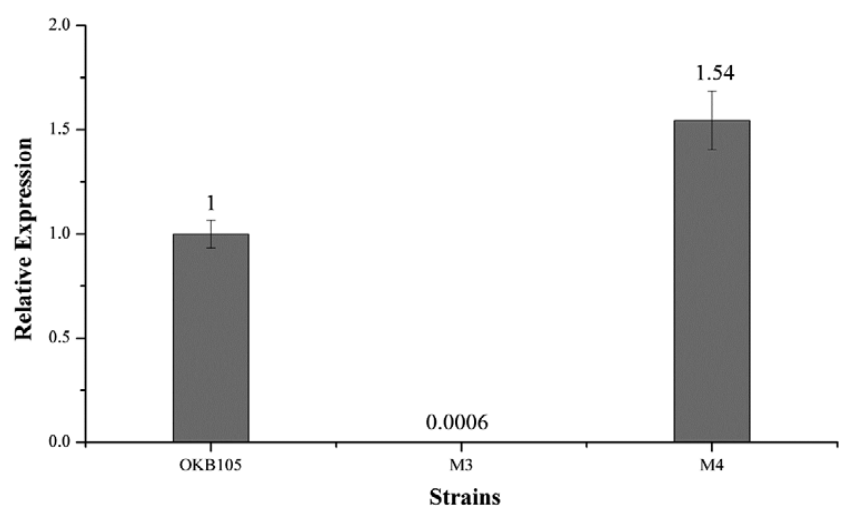

Fig. 3. Expression level of speB in Bacillus subtilis OKB 105 and its derivatives. $\mathrm{M} 3=$ site-directed mutant $\mathrm{OKB} 105 \Delta$ spe $B$ and $\mathrm{M} 4=$ comple-

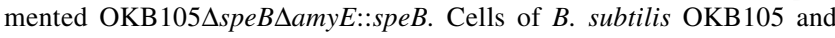
its derivatives were harvested for extracting total RNA and then expression of speB gene in B. subtilis OKB105 and its derivatives were detected. Statistical difference is analysis with Fisher's least significant difference at $P \leq 0.05$.

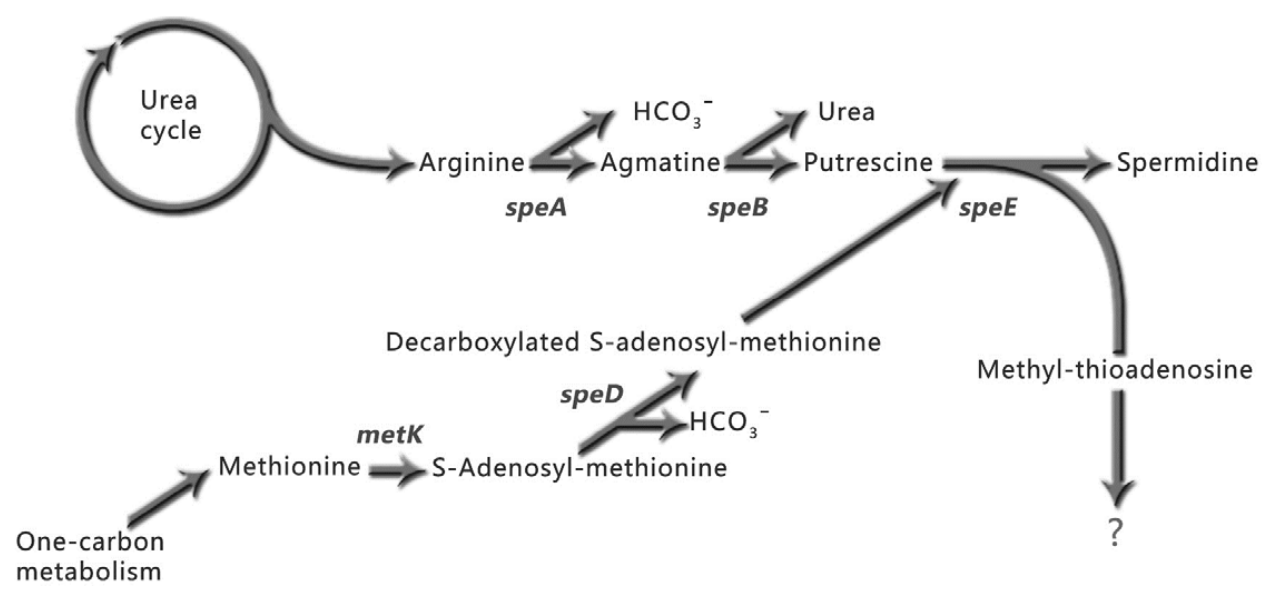

Fig. 2. Polyamines biosynthetic pathway in Bacillus subtilis (Sekowska et al. 1998). 
ethylene production in tobacco (Table 1). Ethylene inhibits hypocotyl and root elongation in etiolated pea seedlings and numerous other plants (Abeles et al. 1992; Guzman and Ecker 1990). These results suggest that the reduction of ethylene content in tobacco may partially reveal the growth-promoting mechanism of spermidine.

\section{DISCUSSION}

Numerous studies have demonstrated that Bacillus spp. can stimulate plant growth by increasing mineral availability in the soil, producing plant hormones (Gutiérrez-Mañero et al. 2001; Idris et al. 2007; Ortíz-Castro et al. 2008), decreasing plant ethylene levels by producing 1-aminocyclopropane1-carboxylate deaminase (Saleem et al. 2007), and releasing

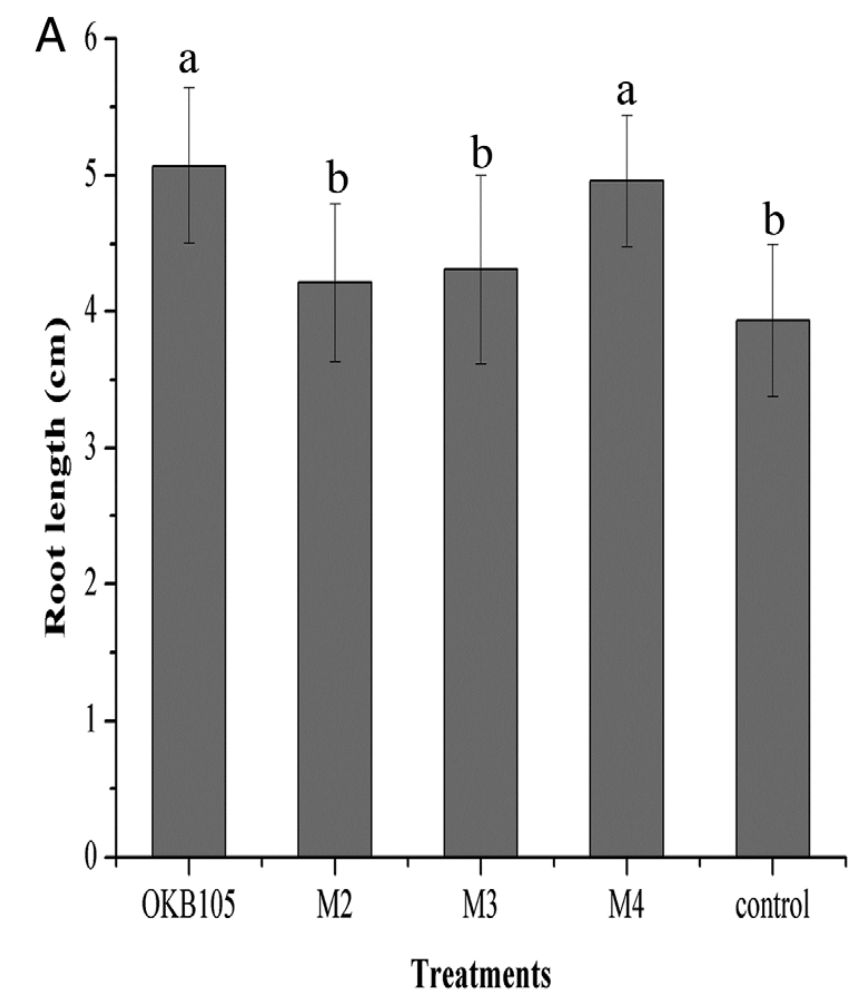

Treatments volatiles such as 3-hydroxy-2-butanone and 2,3-butanediol (Ryu et al. 2003). In our previous study, we demonstrated that plant-growth-promoting activity of B. subtilis OKB105 was not due to the mechanisms already known, and the mechanism of $B$. subtilis OKB105 to stimulate plant growth remained unclear. Therefore, we presume that some special substance produced by OKB105 could contribute to the beneficial effect. To find this substance, the mutant library and HPLC analysis were used. The results had showed that spermidine, a kind of common polyamine, was the pivotal plant-growth-promoting substance produced by $B$. subtilis OKB105. However, spermidine is not detected in the culture filtrates of $B$. amyloliquefaciens FZB42. This may indicate that Bacillus spp. promoting plant growth by producing polyamine is not universally applicable.

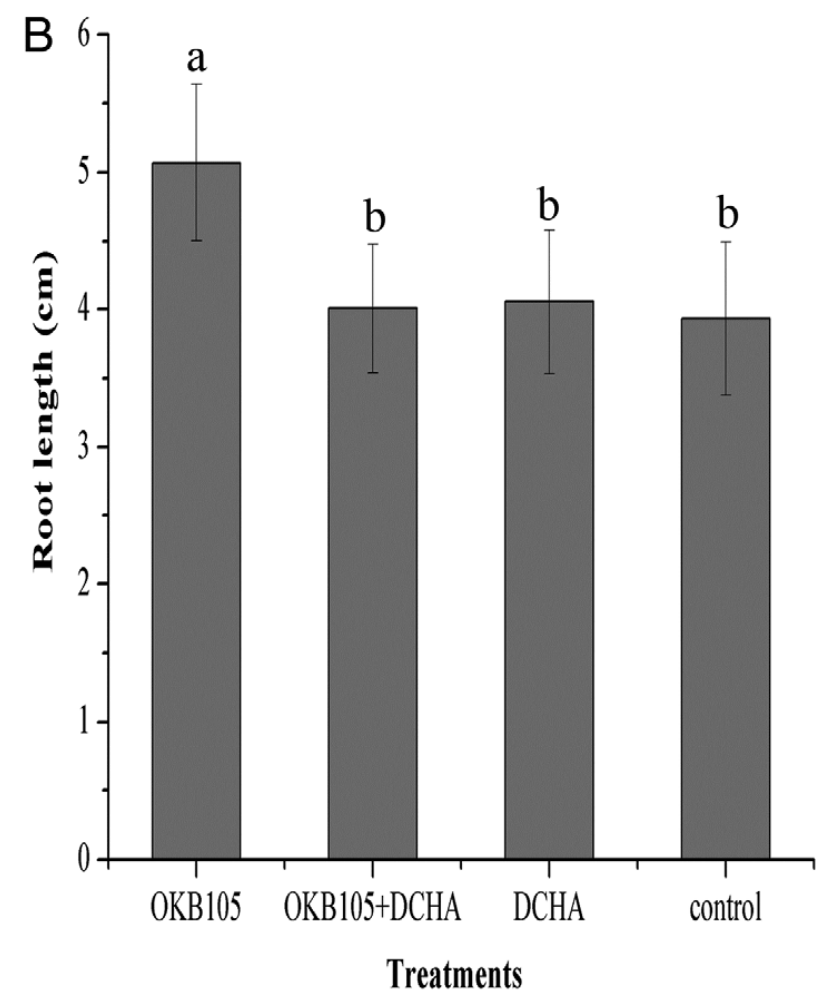

Fig. 4. Growth promotion of Nicotiana tabacum treated with $\mathbf{A}$, Bacillus subtilis OKB105 and mutant strains and $\mathbf{B}$, an inhibitor of spermidine synthase,

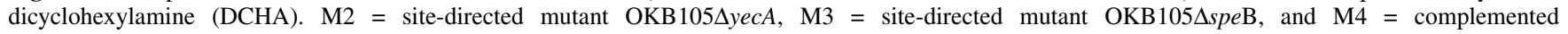

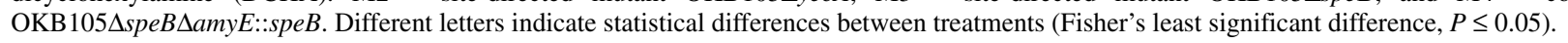
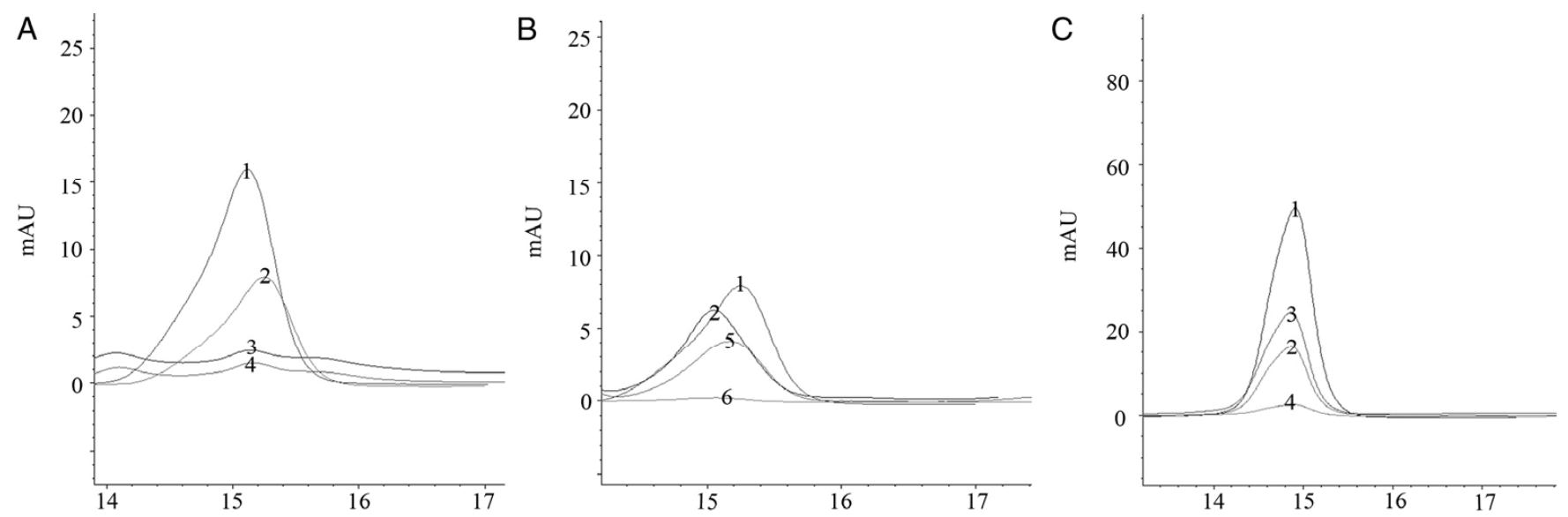

Fig. 5. High-performance liquid chromatography analysis of spermidine from $\mathbf{A}$ and $\mathbf{B}$, culture filtrates or C, intracellular of Bacillus subtilis OKB105 and

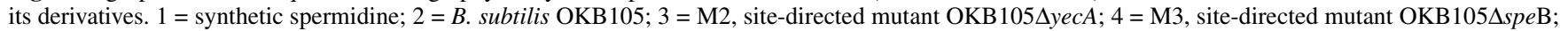

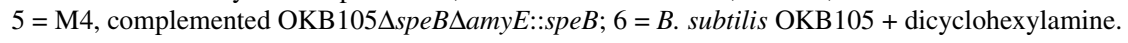


Bacteria polyamines play an important role against various stresses, including acidic and oxidative stresses. In Escherichia coli, the arginine and agmatine involved in the synthesis of polyamine pathway are associated with acid-resistance systems (Foster 2004). Transcription profiles of B. subtilis show that genes associated with polyamine acetylation, transport, and biosynthesis were differentially expressed when growing in acid or alkaline conditions (Wilks et al. 2009). In E. coli, polyamines can protect cells from oxidative stress through upregulating the expression of the oxidative stress-related genes (Tkachenko et al. 2001). Therefore, it is likely that polyamines secreted by bacteria play an important role in increasing their ecological fitness through enhancing tolerance from various stresses.

In addition, some evidence for a link between polyamines and biofilm formation has been proposed. Polyamine depletion in the $\Delta s p e A$ strain resulted in deficiency of biofilm formation, and the defect can be restored by adding agmatine or spermidine into the medium (Burrell et al. 2010). Studies have confirmed that biofilm formation by PGPR plays an important role in protecting plants. For example, B. subtilis ATCC6051 has been shown to form biofilm-like structures on the roots of Arabidopsis plants and protect Arabidopsis from pathogen attacks (Bais et al. 2004). It is reported that plant protection by $B$. subtilis strains depended on widely conserved genes required for biofilm formation, including genes for regulation and matrix production (Chen et al. 2012). This indicates that polyamines produced by bacteria may have an indirect role in protecting plants from pathogen attacks.

In addition to effects on bacterial ecological fitness and biofilm formation, polyamines can promote plant growth as well. In order to understand how polyamine produced by OKB105 stimulated plant growth, we measured the expression of some genes and ethylene content in plant. Generally, we found that two plant expansin genes, Nt-EXPAl and NtEXPA2, were upregulated, the ACO1 gene was downregulated, and the ethylene content was reduced by culture filtrates of B. subtilis OKB105, the wild-type complemented mutant, and synthetic spermidine, respectively. The reduction of ethylene content and the expression of expansin genes might manifest that the spermidine produced by OKB105 enhanced tobacco root growth to a certain extent via inducing expansin expression and decreasing ethylene levels in plant cells. There is some relationship between polyamine and hormone. Ethylene treatment can cause a decrease in the affinity of the arginine decarboxylase for arginine (Apelbaum et al.

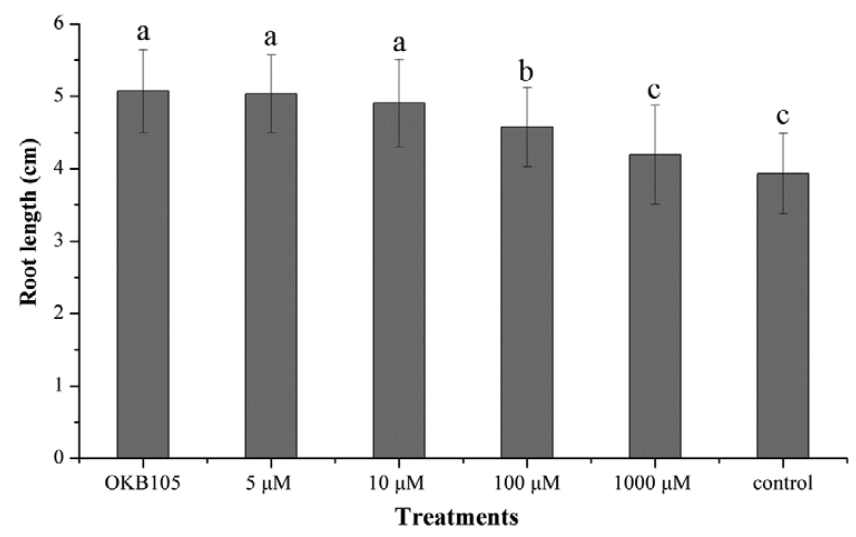

Fig. 6. Growth promotion of Nicotiana tabacum treated with Bacillus subtilis OKB105 and synthetic spermidine. Tobacco (N. tabacum) seed were first soaked with $B$. subtilis OKB105 and spermidine in concentrations varying from 5 to $100 \mu \mathrm{M}$. Root lengths were measured at 20 days. Different letters indicate statistical differences between treatments (Fisher's least significant difference, $P \leq 0.05)$.
1985), and ethylene production in apple fruit and protoplasts and in leaf tissue is inhibited by spermidine or spermine (Apelbaum et al. 1981). Applied gibberellin (GA) enhances polyamine biosynthesis as well as the activity of enzymes in-
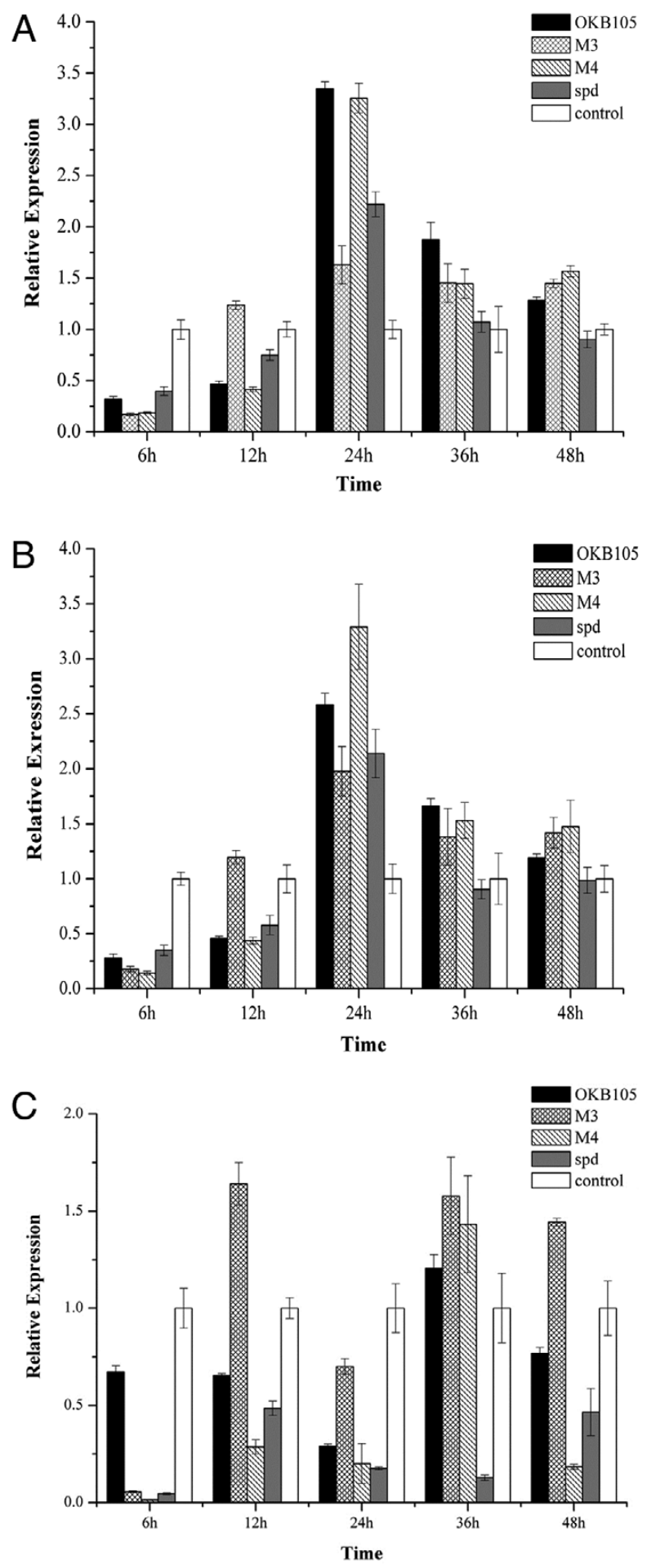

Fig. 7. Real-time polymerase chain reaction analysis of expression of $\mathbf{A}$, Nt-EXPA1; B, Nt-EXPA2; and C, ACO1 in Nicotiana tabacum in response to Bacillus subtilis $\mathrm{OKB} 105$ and its derivatives. M3 = sitedirected mutant $B$. subtilis OKB105 speB, M4 = complemented $B$. subtilis $\mathrm{OKB} 105 \Delta$ speB $\Delta a m y E:: s p e B$, and $\mathrm{spd}=5 \mu \mathrm{M}$ spermidine. Plants (20 days old) were treated with Bacillus spp. culture filtrates and $5 \mu \mathrm{M}$ synthetic spermidine, and the total RNA of tobacco was isolated after treating for $6,12,24,36$, and $48 \mathrm{~h}$. The Landy medium was used as control. Statistical difference is analysis with Fisher's least significant difference at $P \leq 0.05$. 
Table 1. Influence of Bacillus subtilis OKB105 and its derivatives on ethylene content in tobacco ${ }^{\mathrm{z}}$

\begin{tabular}{|c|c|c|}
\hline \multirow[b]{2}{*}{ Treatments } & \multicolumn{2}{|c|}{ Ethylene content ( $\mu \mathrm{g} / \mathrm{g}$ fresh weight) } \\
\hline & 1 day & 3 days \\
\hline B. subtilis $\mathrm{OKB} 105$ & $0.5493 \pm 0.1434 \mathrm{c}$ & $0.8961 \pm 0.0140 \mathrm{~b}$ \\
\hline 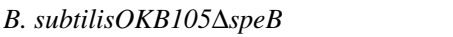 & $0.6879 \pm 0.0706 \mathrm{~b}$ & $0.9466 \pm 0.2130 \mathrm{ab}$ \\
\hline 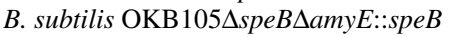 & $0.3411 \pm 0.0463 \mathrm{c}$ & $0.8407 \pm 0.2361 b$ \\
\hline Spermidine & $0.3575 \pm 0.0887 \mathrm{c}$ & $0.7818 \pm 00367 \mathrm{~b}$ \\
\hline Control & $1.1130 \pm 0.2668 \mathrm{a}$ & $1.1287 \pm 0.0239 \mathrm{a}$ \\
\hline
\end{tabular}

${ }^{\mathrm{z}}$ Five-week-old plants were root drenched with culture filtrates of OKB105 or its derivatives, and then the ethylene content in tobacco was measured after treating for 1 and 3 days, respectively. Values are means of ethylene content from three experiments. Different letters indicate statistical differences between treatments (Fisher's least significant difference; $P \leq 0.05$ ).

Table 2. Bacterial strains and plasmids

\begin{tabular}{|c|c|c|}
\hline Bacteria & Relevant genotype or characteristic ${ }^{\mathrm{z}}$ & Sources or references \\
\hline \multicolumn{3}{|l|}{ Strains } \\
\hline \multicolumn{3}{|c|}{ Bacillus subtilis } \\
\hline OKB105 & pheA1 $s f p+$, surfactin producer, JH642 transformed with DNA of ATCC 21332 & Mootz et al.2001; Nakano et al. 1988 \\
\hline M1 & Random mutant OKB105yecA::TnYLB-1 & This study \\
\hline M2 & 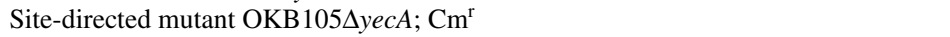 & This study \\
\hline M3 & 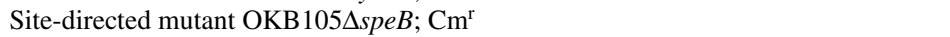 & This study \\
\hline M4 & 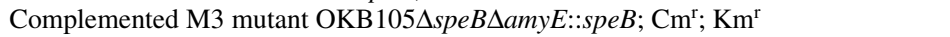 & This study \\
\hline \multicolumn{3}{|c|}{ 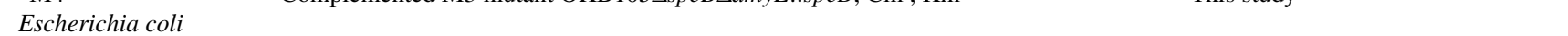 } \\
\hline $\mathrm{DH} 5 \alpha$ & supE44, $\Delta$ lacU 169 ( $\varphi 80$ lacZ M15) hsd R17 rec A1 gyrA96 thi-1 relA91 endA1 & TaKaRa Bio Inc. \\
\hline \multicolumn{3}{|c|}{ 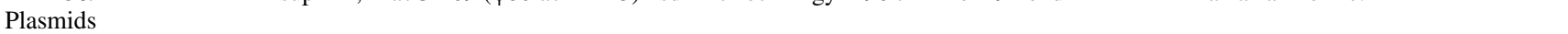 } \\
\hline pMarA & $\begin{array}{l}\text { Shuttle vector carrying TnYLB-1 transposon and mariner-Himar } 1 \text { transposon; pUC } \\
\text { replicon, thermosensitive replicon for Gram-positive hosts; } \mathrm{Km}^{\mathrm{r}} ; \mathrm{Ap}^{\mathrm{r}} ; \mathrm{Em}^{\mathrm{r}}\end{array}$ & Le Breton et al. 2006 \\
\hline pUC18 & E. coli cloning vector; lacZ; $\mathrm{Ap}^{\mathrm{r}}$ & Stored in this lab \\
\hline
\end{tabular}

${ }^{\mathrm{z}} \mathrm{Cm}^{\mathrm{r}}, \mathrm{Km}^{\mathrm{r}}, \mathrm{Ap}^{\mathrm{r}}$, and $\mathrm{Em}^{\mathrm{r}}$ indicate resistant to chloramphenicol, kanamycin, ampicillin, and erythromycin, respectively.

volved in polyamine biosynthesis (Dai et al. 1982). In addition to their effect on plant hormones, polyamines can also increase plant cell division. Higher rooting frequency and mitiotic index are obtained from root tissues of Virginia pine by adding polyamines (Tang and Newton 2005). Researches on model plant tobacco present the sites and regulation of polyamine catabolism related to cell division or expansion, cell cycle progression, and vascular development (Paschalidis and Roubelakis-Angelakis 2005).

Additionally, polyamines can protect plants against various stresses, including oxidative, acidic, osmotic, and neuronal stresses. For instance, exogenously applied polyamines protect plants from salt stress. Spermidine and spermine significantly prevent the leakage of electrolytes and amino acids from roots and shoots induced by salinity stress, and prevent chlorophyll loss as well (Chattopadhayay et al. 2002). The Arabidopsis acl5/spms mutant plant, which is unable to produce spermine, is hypersensitive to salt and drought stresses relative to the wild-type plant (Yamaguchi et al. 2006, 2007).

Because polyamines have several functions, as listed above, we suppose that bacterial spermidine synthesis contributes to i) increasing their own ecological fitness, ii) protecting plants by influence biofilm formation, and iii) promoting plant growth by stimulating expansin expression and influence on plant hormone and increasing cell division. However, further studies will be required to confirm that.

\section{MATERIALS AND METHODS}

Bacteria strains, plasmids, and growth conditions.

The bacterial strains and plasmids employed in this study are described in Table 2. The pMarA shuttle plasmid carries the TnYLB-1 transposon, the mariner-Himarl transposase, and a gram-positive thermosensitive replicon (Le Breton et al. 2006). Bacillus spp. strains were cultured at $30^{\circ} \mathrm{C}$ for $38 \mathrm{~h}$ in Landy medium supplemented (when required) with chloramphenicol $(\mathrm{Cm})\left(5 \mu \mathrm{g} \mathrm{ml}^{-1}\right)$, kanamycin $(\mathrm{Km})\left(5 \mu \mathrm{g} \mathrm{ml}^{-1}\right)$,

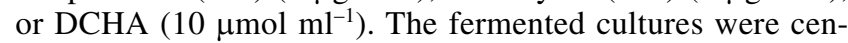

trifuged at $12,000 \mathrm{rpm}$ for $10 \mathrm{~min}$ at $4^{\circ} \mathrm{C}$ and the supernatants were collected and tested for their plant-growth-promoting activity.

\section{Construction and screening of mutant library.}

To construct a B. subtilis OKB105 mutant library, the pMarA shuttle plasmid was transformed into OKB105 strain. Transformant colonies were incubated overnight in LuriaBertani (LB) liquid at $37^{\circ} \mathrm{C}$, and then plated on LB agar containing $\mathrm{Km}$ and incubated at $50^{\circ} \mathrm{C}$ for selecting (Le Breton et al. 2006).

Tobacco (Nicotiana tabacum) seed were soaked in Bacillus spp. culture filtrates or Landy medium for $12 \mathrm{~h}$. The seed were then surface sterilized for $5 \mathrm{~min}$ in a $5 \%$ (wt/vol) solution of sodium hypochlorite, washed three times with sterilized distilled water, spread out evenly on Murashige-Skoog (MS) medium in a square petri dish, and incubated in a light incubator $\left(200 \mu \mathrm{E} \mathrm{m}^{-2} \mathrm{~s}^{-1}\right.$ at $\left.25^{\circ} \mathrm{C}\right)$ with a cycle of $16 \mathrm{~h} /$ day and $8 \mathrm{~h} /$ night (Wang et al. 2009). Root lengths of tobacco were measured after 20 days, and we used Fisher's test to analyze significance of difference. Bacillus mutants defective in promoting plant root growth could be selected.

Spermidine and DCHA were also used to soak the tobacco seed to evaluate their influence on plant growth. The experiments were repeated three times (biological replications), and each treatment had five replications.

\section{Construction of plasmids and strains.}

To generate the site-directed mutant OKB105_yecA M2, two partial sequence fragments of the yecA gene were amplified from OKB105 chromosomal DNA; the sequences of Cm were obtained from pAD43-25. The recombinant fragments were fused by overlap extension PCR and transformed into the OKB105 strain to generate the site-directed mutant M2. The site-directed mutant OKB105 $\Delta$ speB M3 was generated by the same method.

For complementation of the M3 mutant, the entire speB gene was amplified from strain OKB105 chromosomal DNA. 
Table 3. DNA primers used in this study

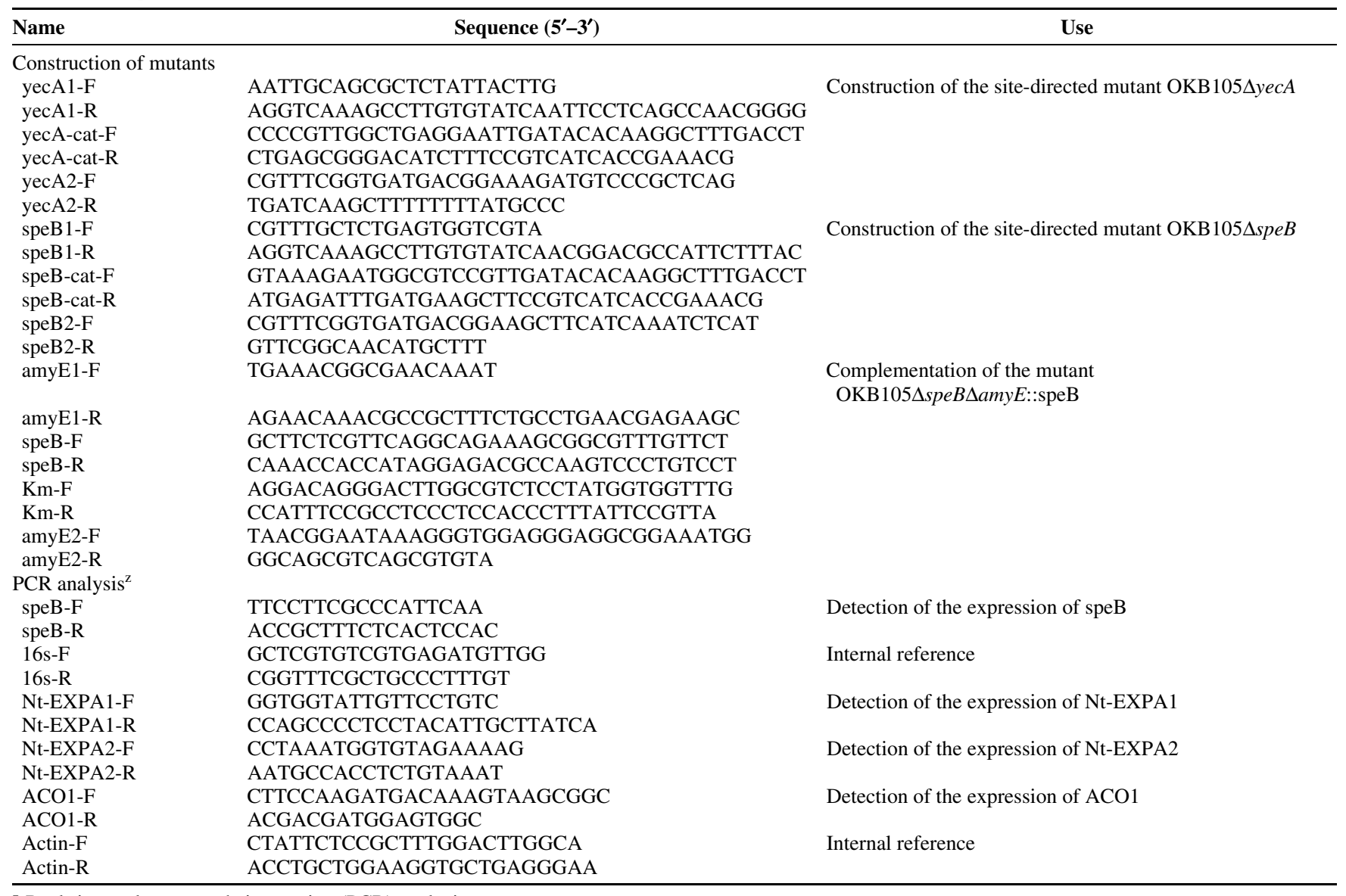

${ }^{\mathrm{z}}$ Real-time polymerase chain reaction (PCR) analysis.

The two homologous recombination arms were obtained from the amyE gene of $B$. subtilis OKB105, and the Km-resistance sequence was cloned from the pMK3 plasmid. The recombinant sequence was fused by overlap extension PCR and transformed into the M3 strain to produce the complemented mutant M4.

The specific primers used above are shown in Table 3 .

\section{Identification and quantification of spermidine.}

Bacillus spp. cells were treated with lysozyme $(10 \mathrm{mg} / \mathrm{ml})$ and then sonicated to disruption in $0.1 \mathrm{M} \mathrm{HCl}$. Lysates or culture filtrates of Bacillus spp. was treated with pure perchloric acid to obtain a $5 \%$ (wt/vol) solution and centrifuged at 8,000 $\times g$ for $30 \mathrm{~min}$. Then, $10-\mathrm{ml}$ samples of supernatant were neutralized with $20 \mathrm{ml}$ of $2 \mathrm{M}$ sodium hydroxide, followed by the addition of $140 \mu \mathrm{l}$ of benzoyl chloride, and the samples were incubated at $37^{\circ} \mathrm{C}$ for $30 \mathrm{~min}$. Then, $10 \mathrm{ml}$ of saturated sodium chloride solution was added to each sample. Benzoyl-amides were extracted in $15 \mathrm{ml}$ of ethyl ether. The organic phase was evaporated, and the sample was resuspended in $100 \mu \mathrm{l}$ of methanol. Then, a 20- $\mu$ l sample was injected into an Agilent HPLC system equipped with a $5-\mu \mathrm{m}$ C18 reverse-phase column and a UV detector set at $254 \mathrm{~nm} ; 60 \%$ methanol was used as the mobile phase at a flow rate of $0.7 \mathrm{ml} \mathrm{min} \mathrm{m}^{-1}$, and the column temperature was $30^{\circ} \mathrm{C}$.

\section{Real-time PCR analysis.}

Bacillus spp. cells were harvested, culturing at $30^{\circ} \mathrm{C}$ for 38 $\mathrm{h}$ in Landy medium. Total RNA was extracted using the Bacterial RNA Kit (Omega Bio-Tek, Norcross, GA, U.S.A.) according to the manufacturer's instructions. First-strand cDNA was obtained using reverse transcriptase (TaKaRa Bio Inc., Tokyo), with random hexamer primers. Real-time PCR was performed with SYBR Premix Ex Taq (TaKaRa Bio Inc.) using a 7500 Fast Real-time PCR System. The $16 \mathrm{~s}$ gene was used as an internal reference in the real-time PCR.

Tobacco seed were surface sterilized, spread out evenly on solid MS medium in a square petri dish, and incubated in an illuminating incubator $\left(200 \mu \mathrm{E} \mathrm{m}^{-2} \mathrm{~s}^{-1}\right.$ at $\left.25^{\circ} \mathrm{C}\right)$ with a cycle of $16 \mathrm{~h} /$ day and $8 \mathrm{~h} /$ night for 20 days. The tobacco seedlings were then treated with Bacillus spp. culture filtrates and $5 \mu \mathrm{M}$ synthetic spermidine, and total RNA from the tobacco was isolated after $6,12,24,36$, or $48 \mathrm{~h}$ of treatment. Landy medium was used for the control. Extraction of RNA was performed using a Plant RNA Kit (Omega Bio-Tek) according to the manufacturer's instructions. First-strand cDNA was obtained using reverse transcriptase (TaKaRa Bio Inc.), with oligo dT primer as primers. Real-time PCR was performed with SYBR Premix Ex Taq (TaKaRa Bio Inc.) using a 7500 Fast Real-time PCR System. The Actin gene was used as an internal reference in the real-time PCR. Real-time PCR analysis was performed to detect the expression levels of Nt-EXPA1, Nt-EXPA2, and $A C O 1$ in tobacco.

\section{Quantification of ethylene content in tobacco.}

Tobacco seed were surface sterilized and grown on solid MS medium for 20 days. Then, each seedling was transplanted to soil. Five weeks after transplanting, the plants were root drenched with culture filtrates of OKB105, its derivatives, and $5 \mu \mathrm{M}$ synthetic spermidine. The ethylene content in the tobacco was measured using a plant ETH ELISA kit (ColorfulGene Bio Tek, Wuhan, China) 1 and 3 days after treatment. 


\section{ACKNOWLEDGMENTS}

This work was supported by grants from the Special Fund for AgroScientific Research in the Public Interest (20130315), the Fundamenta Research Funds for the Central Universities (KYZ201404), the National Natural Science Foundation of China (31100056), the Doctoral Fund of Ministry of Education of China (20100097120011), and the National High-Tech R\&D Program of China (2012AA101504). We thank R. Borriss for assistance with modifying paper and offering suggestions.

\section{LITERATURE CITED}

Abeles, F. B., Morgan, P. W., and Saltveit, M. E., Jr. 1992. Ethylene in Plant Biology. Academic Press, San Diego, CA, U.S.A.

Apelbaum, A., Burgoon, A. C., Anderson, J. D., Lieberman, M., BenArie, R., and Mattoo, A. K. 1981. Polyamine inhibit biosynthesis of ethylene in higher plant tissue and fruit protoplasts. Plant Physiol. 62:453-456.

Apelbaum, A., Goldlust, A., and Icekson, I. 1985. Control by ethylene of arginine decarboxylase activity in pea seedlings and its implication for hormonal regulation of plant growth. Plant Physiol. 79:635-640.

Bais, H. P., Fall, R., and Vivanco, J. M. 2004. Biocontrol of Bacillus subtilis against infection of Arabidopsis roots by Pseudomonas syringae is facilitated by biofilm formation and surfactin production. Plant Physiol. 134:307-319.

Brannen, P., and Kenney, D. 1997. Kodiak-A successful biological-control product for suppression of soil-borne plant pathogens of cotton. J. Ind. Microbiol. Biotechnol. 19:169-171.

Burrell, M., Hanfrey, C. C., Murray, E. J., Stanley-Wall, N. R., and Michael, A. J. 2010. Evolution and multiplicity of arginine decarboxylases in polyamine biosynthesis and essential role in Bacillus subtilis biofilm formation. J. Biol. Chem. 285:39224-39238.

Cassan, F., Maiale, S., Masciarelli, O., Vidal, A., Luna, V., and Ruiz, O. 2009. Cadaverine production by Azospirillum brasilense and its possible role in plant growth promotion and osmotic stress mitigation. Eur. J. Soil Biol. 45:12-19.

Chattopadhayay, M. K., Tiwari, B. S., Chattopadhyay, G., Bose, A., Sengupta, D. N., and Ghosh, B. 2002. Protective role of exogenous polyamines on salinity-stressed rice (Oryza sativa) plants. Physiol. Plant. 116:192-199.

Chen, X.-H., Scholz, R., Borriss, M., Junge, H., Mögel, G., Kunz, S., and Borriss, R. 2009. Difficidin and bacilysin produced by plant-associated Bacillus amyloliquefaciens are efficient in controlling fire blight disease. J. Biotechnol. 140:38-44.

Chen, Y., Yan, F., Chai, Y., Liu, H., Kolter, R., Losick, R., and Guo, J. H. 2012. Biocontrol of tomato wilt disease by Bacillus subtilis isolates from natural environments depends on conserved genes mediating biofilm formation. Environ. Microbiol. 15:848-864.

Choi, D., Lee, Y., Cho, H.-T., and Kende, H. 2003. Regulation of expansin gene expression affects growth and development in transgenic rice plants. Plant Cell 15:1386-1398.

Cosgrove, D. J. 2005. Growth of the plant cell wall. Nat. Rev. Mol. Cell Biol. 6:850-861.

Dai, Y.-R., Kaur-sawhney, R., and Galston, A. W. 1982. Promotion by gibberellic acid of polyamine biosynthesis in internodes of light-grown dwarf peas. Plant Physiol. 69:103-105.

Fan, B., Carvalhais, L. C., Becker, A., Fedoseyenko, D., von Wirén, N., and Borriss, R. 2012. Transcriptomic profiling of Bacillus amyloliquefaciens FZB42 in response to maize root exudates. BMC Microbiol. $12: 116$

Foster, J. W. 2004. Escherichia coli acid resistance: Tales of an amateur acidophile. Nat. Rev. Microbiol. 2:898-907.

Gutiérrez-Mañero, F. J., Ramos-Solano, B., Probanza, A., Mehouachi, J., R Tadeo, F., and Talon, M. 2001. The plant-growth-promoting rhizobacteria Bacillus pumilus and Bacillus licheniformis produce high amounts of physiologically active gibberellins. Physiol. Plant. 111:206-211.

Guzman, P., and Ecker, J. R. 1990. Exploiting the triple response of Arabidopsis to identify ethylene-related mutants. Plant Cell 2:513523.

Hibasami, H., Tanaka, M., Nagai, J., and Ikeda, T. 1980. Dicyclohexylamine, a potent inhibitor of spermidine synthase in mammalian cells. FEBS (Fed. Eur. Biochem. Soc.) Lett. 116:99-101.

Hummel, I., Couée, I., El Amrani, A., Martin-Tanguy, J., and Hennion, F. 2002. Involvement of polyamines in root development at low temperature in the subantarctic cruciferous species Pringlea antiscorbutica. J. Exp. Bot. 53:1463-1473.

Idris, E. E., Iglesias, D. J., Talon, M., and Borriss, R. 2007. Tryptophandependent production of indole-3-acetic acid (IAA) affects level of plant growth promotion by Bacillus amyloliquefaciens FZB42. Mol. Plant-Microbe Interact. 20:619-626.

Idriss, E. E., Makarewicz, O., Farouk, A., Rosner, K., Greiner, R., Bochow, H., Richter, T., and Borriss, R. 2002. Extracellular phytase activity of Bacillus amyloliquefaciens FZB45 contributes to its plantgrowth-promoting effect. Microbiology 148:2097-2109.

Imai, A., Matsuyama, T., Hanzawa, Y., Akiyama, T., Tamaoki, M., Saji, H., Shirano, Y., Kato, T., Hayashi, H., and Shibata, D. 2004. Spermidine synthase genes are essential for survival of Arabidopsis. Plant Physiol. 135:1565-1573.

Kasukabe, Y., He, L., Nada, K., Misawa, S., Ihara, I., and Tachibana, S. 2004. Overexpression of spermidine synthase enhances tolerance to multiple environmental stresses and up-regulates the expression of various stress-regulated genes in transgenic Arabidopsis thaliana. Plant Cell Physiol. 45:712-722.

Kusano, T., Berberich, T., Tateda, C., and Takahashi, Y. 2008. Polyamines: Essential factors for growth and survival. Planta 228:367-381.

Le Breton, Y., Mohapatra, N. P., and Haldenwang, W. 2006. In vivo random mutagenesis of Bacillus subtilis by use of TnYLB-1, a marinerbased transposon. Appl. Environ. Microbiol. 72:327-333.

McQueen-Mason, S., Durachko, D. M., and Cosgrove, D. J. 1992. Two endogenous proteins that induce cell wall extension in plants. Plant Cell 4:1425-1433.

Mootz, H. D., Finking, R., and Marahiel, M. A. 2001. 4'-Phosphopantetheine transfer in primary and secondary metabolism of Bacillus subtilis. J. Biol. Chem. 276:37289-37298.

Nakano, M. M., Marahiel, M., and Zuber, P. 1988. Identification of a genetic locus required for biosynthesis of the lipopeptide antibiotic surfactin in Bacillus subtilis. J. Bacteriol. 170:5662-5668.

Ngugi, H., Dedej, S., Delaplane, K., Savelle, A., and Scherm, H. 2005. Efect of flower-applied Serenade biofungicide (Bacillus subtilis) on pollination-related variables in rabbiteye blueberry. Biol. Control 33:32-38.

Ongena, M., Jourdan, E., Adam, A., Paquot, M., Brans, A., Joris, B., Arpigny, J. L., and Thonart, P. 2007. Surfactin and fengycin lipopeptides of Bacillus subtilis as elicitors of induced systemic resistance in plants. Environ. Microbiol. 9:1084-1090.

Ortíz-Castro, R., Valencia-Cantero, E., and López-Bucio, J. 2008. Plant growth promotion by Bacillus megaterium involves cytokinin signaling. Plant Signal. Behav. 3:263-265.

Paschalidis, K. A., and Roubelakis-Angelakis, K. A. 2005. Sites and regulation of polyamine catabolism in the tobacco plant. Correlations with cell division/expansion, cell cycle progression, and vascular development. Plant Physiol. 138:2174-2184.

Pliego, C., De Weert, S., Lamers, G., De Vicente, A., Bloemberg, G., Cazorla, F. M., and Ramos, C. 2008. Two similar enhanced root-colonizing Pseudomonas strains differ largely in their colonization strategies of avocado roots and Rosellinia necatrix hyphae. Environ. Microbiol. 10:3295-3304.

Ramey, B. E., Koutsoudis, M., von Bodman, S. B., and Fuqua, C. 2004. Biofilm formation in plant-microbe associations. Curr. Opin. Microbiol. 7:602-609.

Romero, D., de Vicente, A., Rakotoaly, R. H., Dufour, S. E., Veening, J.W., Arrebola, E., Cazorla, F. M., Kuipers, O. P., Paquot, M., and PérezGarcía, A. 2007. The iturin and fengycin families of lipopeptides are key factors in antagonism of Bacillus subtilis toward Podosphaera fusca. Mol. Plant-Microbe Interact. 20:430-440.

Rudrappa, T., Czymmek, K. J., Paré, P. W., and Bais, H. P. 2008. Rootsecreted malic acid recruits beneficial soil bacteria. Plant Physiol. 148:1547-1556.

Ryu, C.-M., Farag, M. A., Hu, C.-H., Reddy, M. S., Wei, H.-X., Paré, P. W., and Kloepper, J. W. 2003. Bacterial volatiles promote growth in Arabidopsis. Proc. Natl. Acad. Sci. U.S.A. 100:4927-4932.

Saleem, M., Arshad, M., Hussain, S., and Bhatti, A. S. 2007. Perspective of plant growth promoting rhizobacteria (PGPR) containing ACC deaminase in stress agriculture. J. Ind. Microbiol. Biotechnol. 34:635-648.

Sekowska, A., Bertin, P., and Danchin, A. 1998. Characterization of polyamine synthesis pathway in Bacillus subtilis 168. Mol. Microbiol. 29:851-858.

Tang, W., and Newton, R. J. 2005. Polyamines promote root elongation and growth by increasing root cell division in regenerated Virginia pine (Pinus virginiana Mill.) plantlets. Plant Cell Rep. 24:581-589.

Tkachenko, A., Nesterova, L., and Pshenichnov, M. 2001. The role of the natural polyamine putrescine in defense against oxidative stress in Escherichia coli. Arch. Microbiol. 176:155-157.

Torrigiani, P., Serafini-Fracassini, D., and Bagni, N. 1987. Polyamine biosynthesis and effect of dicyclohexylamine during the cell cycle of Helianthus tuberosus tuber. Plant Physiol. 84:148-152.

Van Peer, R., Niemann, G., and Schippers, B. 1991. Induced resistance and phytoalexin accumulation in biological control of Fusarium wilt of 
carnation by Pseudomonas sp. strain WCS 417r. Phytopathology 81:728-734

Wang, S., Wu, H., Qiao, J., Ma, L., Liu, J., Xia, Y., and Gao, X. 2009. Molecular mechanism of plant growth promotion and induced systemic resistance to tobacco mosaic virus by Bacillus spp. J. Microbiol. Biotechnol. 19:1250-1258.

Wilks, J. C., Kitko, R. D., Cleeton, S. H., Lee, G. E., Ugwu, C. S., Jones, B. D., BonDurant, S. S., and Slonczewski, J. L. 2009. Acid and base stress and transcriptomic responses in Bacillus subtilis. Appl. Environ. Microbiol. 75:981-990.

Wortham, B. W., Oliveira, M. A., and Patel, C. N. 2007. Polyamines in bacteria: Pleiotropic effects yet specific mechanisms. Adv. Exp. Med.
Biol. 603:106-115.

Yamaguchi, K., Takahashi, Y., Berberich, T., Imai, A., Miyazaki, A., Takahashi, T., Michael, A., and Kusano, T. 2006. The polyamine spermine protects against high salt stress in Arabidopsis thaliana. FEBS (Fed. Eur. Biochem. Soc.) Lett. 580:783-788.

Yamaguchi, K., Takahashi, Y., Berberich, T., Imai, A., Takahashi, T., Michael, A., and Kusano, T. 2007. A protective role for the polyamine spermine against drought stress in Arabidopsis. Biochem. Biophys. Res. Commun. 352:486-490.

Yoda, H., Yamaguchi, Y., and Sano, H. 2003. Induction of hypersensitive cell death by hydrogen peroxide produced through polyamine degradation in tobacco plants. Plant Physiol. 132:1973-1981. 